\title{
Failure of national antenatal vitamin D supplementation programme puts dark skinned infants at highest risk: A newborn bloodspot screening study
}

Suma Uday ${ }^{1,2}$, Sunia Naseem ${ }^{3}$, Jamie Large ${ }^{3}$, Russell Denmeade ${ }^{4}$, Philippa Goddard ${ }^{4}$, Mary Anne Preece ${ }^{4}$, Rachel Dunn ${ }^{5}$, William Fraser ${ }^{5,6}$, Jonathan C Y Tang ${ }^{5}$, Wolfgang Högler ${ }^{2,7}$

1. Department of Endocrinology and Diabetes, Birmingham Women's and Children's Hospital, Steelhouse lane, Birmingham, B4 6NH, UK

2. Institute of Metabolism and Systems Research, University of Birmingham, Edgbaston, Birmingham, B15 2TT, UK

3. College of Medical and Dental Sciences, University of Birmingham, Edgbaston, Birmingham, B15 2TT, UK

4. Department of Newborn Screening and Biochemical Genetics, Birmingham Women's and Children's Hospital, Steelhouse lane, Birmingham, B4 6NH, UK

5. Department of Medicine, Norwich Medical School, University of East Anglia, Norwich Research Park, Norwich NR4 7UQ, UK

6. Departments of Diabetes and Endocrinology and Clinical Biochemistry, Norfolk and Norwich University Hospital, Norwich NR4 7UY

7. Department of Paediatrics and Adolescent Medicine, Johannes Kepler University Linz, 4020 Linz, Austria

\section{Corresponding author:}

Dr. Suma Uday

Department of Endocrinology and Diabetes,

Birmingham Women's and Children's Hospital,

Steelhouse lane, Birmingham, B4 6NH

Tel: $0121333999 \quad$ E-mail: suma.uday@nhs.net

\author{
Abstract: 396 \\ Manuscript word count: 3437 \\ Total figures: 3 Colour figures: 2 Tables: 2
}




\begin{abstract}
Objectives: To determine the prevalence of vitamin D deficiency on dried blood spots (DBS) obtained at newborn bloodspot screening (NBS) and thereby test the efficacy of the UK national antenatal supplementation programme in an increasingly ethnically diverse English population. To evaluate the seasonal and ethnic variation in neonatal plasma 25 hydoxyvitamin $\mathrm{D}(25 \mathrm{OHD})$ and its determinants.
\end{abstract}

Design: Three thousand random DBS samples received at a single regional newborn screening laboratory $\left(52^{\circ} \mathrm{N}\right)$ over two one-week periods, one in winter (February 2019) and one in summer (August 2019), were collected. Data was collected from NBS cards on birth weight, gestational age, maternal age, ethnicity, and post code which was replaced with index of multiple deprivation (IMD). 25OHD concentrations were measured on 6mm sub-punch from DBS using quantitative liquid chromatography tandem mass spectrometry adjusted to equivalent plasma values. 25OHD variation with season was assessed using Mann-Whitney U test and ethnic groups compared using Kruskal-Wallis test. Linear regression was used to assess the determinants of 25OHD concentrations.

Results: 25OHD measurements were available in 2999 (1580 males) subjects [1499 winterborn and 1500 summer-born]. The majority were white British (59.1\%) and born at term (mean \pm SD gestational age of $38.8 \pm 1.8$ weeks) with a mean $( \pm$ SD) birth weight of $3306( \pm 565)$ grams. The overall prevalence of vitamin D deficiency [25OHD $<30 \mathrm{nmol} / \mathrm{L}(12 \mu \mathrm{g} / \mathrm{L})]$ was $35.7 \%$ $(\mathrm{n}=1070)$ and insufficiency $[30-50 \mathrm{nmol} / \mathrm{L}(12-20 \mu \mathrm{g} / \mathrm{L})] 33.7 \%(\mathrm{n}=1010)$. The median (IQR) $25 \mathrm{OHD}$ concentration was significantly lower in the winter-born compared to summer-born [29.1 $(19.8,40.6)$ vs $49.2(34.3,64.8) \mathrm{nmol} / \mathrm{L}$ respectively; $\mathrm{p}<0.001]$. Across both seasons, when compared to white British babies (41.6 nmol/L), the median $25 \mathrm{OHD}$ concentrations were significantly lower in babies of black (30.3 nmol/L; $<<0.001)$, Asian (31.3 nmol/L; $<<0.001)$, any other mixed $(32.9 \mathrm{nmol} / \mathrm{L} ; \mathrm{p}<0.001)$, mixed white and black $(33.7 \mathrm{nmol} / \mathrm{L} ; \mathrm{p}<0.05)$ and 
any other white $(37.7 \mathrm{nmol} / \mathrm{L} ; \mathrm{p}<0.05)$ ethnicity. The proportion of deficiency was also higher in babies of Asian (48\%), black (47\%) and mixed ethnicity (38-44\%) compared to any other white (34\%) or white British (30\%) ethnicity. Season of birth, ethnicity, gestation and maternal age accounted for almost $24 \%$ of the variation in $25 \mathrm{OHD}$ concentrations.

Conclusion: The current UK antenatal supplementation programme fails to protect newborns from vitamin D deficiency, especially those from minority ethnic groups who are at high risk of vitamin D deficiency. Nearly $70 \%$ of all newborns and $85 \%$ of winter-borns had $25 \mathrm{OHD}$ concentrations below $50 \mathrm{nmol} / \mathrm{L}(20 \mu \mathrm{g} / \mathrm{L})$. Almost 50\% of babies of Black or Asian origin were deficient at birth, which explains their high risk of hypocalcaemic complications and rickets if left unsupplemented. Our findings call for an immediate review of the delivery of antenatal and infant vitamin D supplementation programmes and implementation of food fortification in the long term.

Keywords: women, neonate, micronutrient, vitamin, cholecalciferol, fortification 


\section{INTRODUCTION}

Neonates with vitamin D deficiency can develop serious life-threatening complications such as hypocalcaemic seizures, dilated cardiomyopathy, cardiac failure and, rarely, death in the first months of life.[1] Additional features include poor feeding, craniotabes, hypotonia and delayed motor milestones.[2] In infants over 6 months, vitamin D deficiency can present with hypocalcaemic (seizure, tetany) and hypophosphataemic complications (rickets with bowing deformities of legs, delayed development).

Due to the high calcium demands of rapid growth in infancy,[3] hypocalcaemia can manifest as early as in the first week of life,[4-6] when the mother was severely vitamin D deficient and did not receive adequate replacement in pregnancy. There is robust evidence base now established which suggests that adequate vitamin D status in pregnancy is essential not only to maintain optimal skeletal health in the mother and her newborn,[7] but also to prevent hypocalcaemia,[8] and rickets in the newborn,[9] and to optimise future bone health of the offspring.[10] There is growing evidence on the effect of vitamin D deficiency on non-skeletal pregnancy-related adverse health outcomes such as gestational diabetes, pre-eclampsia and small for gestation birth.[11-12] It is therefore imperative to ensure adequate vitamin D status during pregnancy and infancy. Given the very few dietary sources of vitamin D, there is reliance on sunlight or supplements, in high latitude countries with limited sunshine. Most developed countries therefore have vitamin D supplementation policies in place for high-risk groups which includes pregnant women (antenatal) and infants (postnatal). Infants are particularly at high risk of vitamin D deficiency not only due to reduced sun-exposure but also because the requirements are not met through feeds alone, especially in breastfed infants.[9] We have previously reported on the ineffectiveness of the UK infant vitamin D supplementation policies compared to other European countries.[13] To date, the success and effectiveness of the UK antenatal supplementation programme remains unknown. The UK 
guidance recommends a $400 \mathrm{IU} /$ day vitamin D supplement in all pregnant women,[14-15] and a 1000 IU/day supplement in high-risk women, including those with darker skin pigmentation.[15]

Vitamin D status in apparently healthy children, particularly infants, is poorly studied due to practical difficulties in obtaining blood samples.[16] In recent years, measuring 25 hydroxyvitamin D (25OHD) on dried blood spot (DBS), obtained through minimally invasive techniques,[17-18] has evolved significantly enabling reliable assessment of population vitamin D status.[19] Measuring neonatal 25OHD on DBS samples collected as part of the national newborn bloodspot screening (NBS) programme is a suitable way of assessing the population prevalence of vitamin D deficiency in this most vulnerable group. This public health study was designed to assess the effectiveness of the UK antenatal supplementation programmes in preventing vitamin D deficiency in the newborn and provide direction to infant supplementation programmes.

\begin{abstract}
$\underline{\text { AIMS }}$
1. Determine the prevalence of $25 \mathrm{OHD}$ deficiency $[<30 \mathrm{nmol} / \mathrm{L}(12 \mu \mathrm{g} / \mathrm{L})]$ in newborns as a key performance indicator of the UK antenatal vitamin D supplementation programme.

2. Assess seasonal and ethnic variation in DBS 25OHD in newborns

3. Study the determinants of $25 \mathrm{OHD}$ in newborns
\end{abstract}

\title{
RESEARCH DESIGN AND METHODS
}

\section{Study Design:}

To collect a representative population sample in an increasingly ethnically diverse population, 3000 DBS samples sent to Birmingham Women's and Children's Hospital's regional newborn 
screening laboratory, in the Midlands region of England $\left(52^{\circ} \mathrm{N}\right)$, were collected after obtaining ethical and relevant regulatory approvals. Data submitted on the NBS cards were gathered following anonymisation. 25OHD concentration on the DBS was measured by quantitative liquid chromatography tandem mass spectrometry (LC-MS/MS) and plasma equivalent values derived.

\section{Study population:}

All babies born in England have a blood spot sample collected on day 5 of life as part of the national NBS programme to screen for a specific set of metabolic diseases. To assess seasonal effects, samples were collected at the end of winter and summer months to capture the anticipated nadir and peak in 25OHD concentrations, respectively. All DBS samples received over one week in winter (last week of February 2019) and one week in summer (last week of August 2019) were retrieved after all routine NBS testing had been completed. Exclusion criteria included: samples marked high risk of infection (e.g. HIV), insufficient samples, second tests including neonates $>21$ days and cases with any missing information.

\section{DBS Samples:}

The samples are collected on a standard Whatman 903 filter paper through a heel prick by an appropriately trained healthcare professional. DBS sample were couriered from maternity services to the screening laboratory on a daily basis with; $90 \%$ of samples being received on the day and all samples within 3 days of collection. Samples were stored at room temperature and away from direct sunlight at all stages (in maternity service, during transportation and on receipt in the screening laboratory). Study samples were obtained within 7 days of receiving in the screening laboratory, stored at $-20^{\circ} \mathrm{C}$ and analysed at the completion of recruitment (October 2019 - December 2019).

\section{Source Data}

Personal data submitted alongside the NBS card is routinely entered and stored by the newborn screening laboratory team in an electronic format. Data provided to the research team was 
anonymised by a member of the newborn screening team. Anonymised data gathered included: birth weight, gestational age, maternal age and ethnic group codes. For complete anonymity, postcodes were replaced by Lower-layer Super Output Area (LSOA) that each postcode falls within, and the deprivation indices for that LSOA.[20] LSOA is a geographic hierarchy designed to improve the reporting of small area statistics and includes a mean population of 1500. The Index of Multiple Deprivation (IMD) is obtained by combining seven domains of deprivation: income, employment, education, health, crime, barriers to housing and services and living environment.[20] Each domain and the IMD can be represented in ranks (1 to $32,844)$ or deciles which are calculated by ranking the 32,844 small areas in England from most deprived to least deprived and dividing them into 10 equal deciles, where 1 is the most deprived and 10 the least deprived.[21]

Ethnicity group codes prescribed by the UK Office of National Statistics were used.[22] The independent ethnic group codes were clubbed and grouped as follows:

Group 1: White British

Group 2: Any other white (white Irish + Any other white)

Group 3: Asian (Indian, Pakistani, Bangladeshi, Chinese and any other Asian background) Group 4: Black (African, Caribbean, any other black background)

Group 5: Mixed white and black (White and black African and white and black Caribbean) Group 6: Mixed white and Asian

Group 7: Any other mixed (any other mixed background and any other ethnicity)

\section{Analysis of DBS 250HD and plasma equivalent values}

Dried blood spot 25OHD3 and 25OHD2 concentrations were measured at the Bioanalytical facility in The University of East Anglia, Norwich, UK, by quantitative LC-MS/MS following extraction methods previously detailed.[18,23] In brief, a $6 \mathrm{~mm}$ sub-punch was made from each 
blood spot sample using a pneumatic DBS card puncher (Analytical Sales \& Services, NJ, USA). Samples were extracted using $300 \mu \mathrm{L}$ of 50:50 (v/v) isopropanol to water solution containing carbon-13 labelled $25 \mathrm{OHD} 3-{ }^{13} \mathrm{C}_{5}$ internal standard; in an ultrasonic water bath at $35^{\circ} \mathrm{C}$ for 30 minutes. The extracts were transferred onto Supported Liquid Extraction (SLE + ) plate (Biotage, Uppsala, Sweden) for further clean up, then eluted with $1.5 \mathrm{~mL}$ of heptane. The eluent was dried to completeness under nitrogen gas heated at $60^{\circ}$, followed by derivatisation with 4-phenyl-1,2,4-triazoline-3,5-dione (PTAD). The PTAD-derivatised 25OHD3 and 25OHD2 were separated using a C18 $2.7 \mu \mathrm{m} .50 \times 2.1 \mathrm{~mm}$ chromatographic column (Restek, PA, USA) and detected using the Micromass Quattro Ultima Pt tandem mass spectrometer (Waters Corp., Milford, MA, USA) according to analyte precursor to product transitions; $607>298$ (25OHD3) and 613>298 (25OHD2). Each batch of sample analysis was performed with matrix-matched calibration standards and quality controls prepared in vitamin D and its hydroxylated metabolite-free packed red cells. The inter/intra-assay coefficient of variation (CV) was between 3.9-9.4\%, across the concentration range of the assay, with linearity from the lower limit of quantification (LLoQ) of $1 \mathrm{nmol} / \mathrm{L}$ up to $150 \mathrm{nmol} / \mathrm{L}$.

Data are reported as plasma equivalent total $25 \mathrm{OHD}$, which was calculated using the following formula: Plasma equivalent total 25OHD nmol/L $=[(\mathrm{DBS} 25 \mathrm{OHD} 3+\mathrm{DBS} 25 \mathrm{OHD} 2 \mathrm{nmol} / \mathrm{L})$ $-1.2607] /(1-0 \cdot 60)$; where 1.2607 is to adjust for the difference in slope between plasma and DBS value,[18] and $0 \cdot 60$ is the mean haematocrit (Hct). Given that 25OHD exists primarily in the extracellular fluid compartment in blood, blood spot measurements for 25OHD must be adjusted for Hct. Owing to the higher Hct in the neonatal period,[24] and specifically in capillary samples,[25] a value of 0.60 was used.

\section{Ethics and consent:}


The study was approved by the UK Health Research Authority (HRA) and the East Midlands - Leicester South Research Ethics Committee (REC Reference 19/EM/0019). The study was also approved by the Antenatal and Newborn Research Advisory Committee of Public Health England, UK. Parental consent was not required as all data acquired were anonymised and compliance with the code of practice for the retention and storage of residual newborn blood spots was ensured.[26]

\section{$\underline{\text { Statistical analysis: }}$}

Descriptive statistics are presented as medians with interquartile ranges (IQR) or mean with standard deviation (SD) for continuous variables, and frequencies with percentages for categorical variables. 25OHD concentrations were used both as a continuous variable and categorical variable, defining deficiency as $<30 \mathrm{nmol} / \mathrm{L}(12 \mu \mathrm{g} / \mathrm{l})$, insufficiency as $30-50$ $\mathrm{nmol} / \mathrm{L}(12-20 \mu \mathrm{g} / \mathrm{l})$ and sufficiency as $>50 \mathrm{nmol} / \mathrm{L}(>20 \mu \mathrm{g} / \mathrm{l})$ according to the Institute Of Medicine,[27] and Global consensus recommendation classifications.[9] Non-parametric tests were used as $25 \mathrm{OHD}$ concentrations were skewed. Whilst normal distribution for 25OHD overall was achieved following square root transformation, the results obtained on parametric tests were comparable and are therefore not reported here.

Mann-Whitney $\mathrm{U}$ test was used to compare 25OHD concentrations between the winter and summer-born groups. The Kruskal-Wallis test was used to compare 25OHD concentrations between the different ethnic groups. The factors that were significant $(\mathrm{p}<0.05)$ on a bivariate analysis were included in the multiple linear regression model. The significant factors included were season of birth, ethnicity, gestational age, maternal age and IMD decile. Ethnicity, gestational age and IMD deciles (1 to 10$)$ were used as categorical variables. Gestational age at birth was categorised as term ( $>37-41$ weeks), extreme pre-term $(<28$ weeks), pre-term (2837 weeks) and post-term ( $>41$ weeks). All analyses were performed using SPSS statistical software v25.0 (IBM, Armonk, NY). 


\section{RESULTS}

25OHD measurements were available on 2999 (1580 males) subjects; 1499 were winter-born and 1500 summer-born. Neonates were between 5 and 19 days old at the time of sample collection. Ninety nine percent of the samples were collected in the first week of life between day 5 and day 7 [93.3\% on D5 $(n=2800), 5.1 \%$ on $\mathrm{D} 6(\mathrm{n}=154)$ and $0.6 \%$ on $\mathrm{D} 7(\mathrm{n}=19)]$. The baseline characteristics are presented in Table 1. The majority were white British (59.1\%) and born at term (mean \pm SD gestational age of $38.8 \pm 1.8$ weeks) with a mean $( \pm$ SD) birth weight of $3306( \pm 565)$ grams. The mean IMD decile was $4.0( \pm 2.7)$ and nearly a quarter of the cohort $(24 \%, \mathrm{n}=720)$ were from the most deprived IMD decile (decile 1$)$. The baseline characteristics did not differ significantly between the winter-born and summer-born groups (Table 1).

\begin{tabular}{|l|l|l|l|l|}
\hline & $\begin{array}{l}\text { Whole study } \\
\text { group }\end{array}$ & Winter-born & Summer-born & P value \\
\hline Numbers & 2999 & $1499 *$ & 1500 & \\
\hline $\begin{array}{l}\text { Number of males (\% of } \\
\text { total) }\end{array}$ & $1580(52.7 \%)$ & $771(51.4 \%)$ & $809(53.9 \%)$ & 0.16 \\
\hline Birth weight in g & $3306(565)$ & $3313(563)$ & $3299(566)$ & 0.49 \\
\hline $\begin{array}{l}\text { Gestational age in } \\
\text { weeks }\end{array}$ & $38.8(1.8)$ & $38.8(1.8)$ & $38.8(1.7)$ & 0.57 \\
\hline Maternal age in years & $30.4(5.5)$ & $30.4(5.6)$ & $30.5(5.4)$ & 0.61 \\
\hline Ethnic groups n (\%) & & & & 0.64 \\
White British & $1774(59.1 \%)$ & $877(58.5 \%)$ & $897(59.8 \%)$ & \\
Any other white & $264(8.8 \%)$ & $134(8.9 \%)$ & $130(8.7 \%)$ & \\
Asian & $494(16.5 \%)$ & $249(16.6 \%)$ & $245(16.4 \%)$ & \\
Black & $173(5.8 \%)$ & $90(6.0 \%)$ & $83(5.5 \%)$ & \\
Mixed white and black & $94(3.1 \%)$ & $53(3.5 \%)$ & $41(2.7 \%)$ & \\
Mixed white and Asian & $45(1.5 \%)$ & $21(1.4 \%)$ & $24(1.6 \%)$ & \\
Any other mixed & $156(5.2 \%)$ & $76(5.1 \%)$ & $80(5.3 \%)$ & \\
\hline $\begin{array}{l}\text { Index of Multiple } \\
\text { Deprivation decile } \\
(1=\text { most deprived to }\end{array}$ & $4.0(2.7)$ & $4.1(2.7)$ & $4.0(2.7)$ & 0.34 \\
10=least deprived) & & & & \\
\hline
\end{tabular}

* One missing sample

Table 1: Baseline characteristics of the whole study group and the winter and summer-born sub-groups. Numbers are reported as mean $( \pm \mathrm{SD})$ or $n(\%)$. 


\section{Prevalence of Vitamin D deficiency}

The median (IQR) 25OHD concentration was $37.8(24.8,54.8) \mathrm{nmol} / \mathrm{L}$. Vitamin D deficiency $(<30 \mathrm{nmol} / \mathrm{L})$ was present in $35.7 \%(\mathrm{n}=1070)$ of the cohort, of whom $6.2 \%(\mathrm{n}=186)$ were severely deficient with concentrations below $12.5 \mathrm{nmol} / \mathrm{L}(5 \mu \mathrm{g} / \mathrm{L})$. Vitamin D insufficiency (30-50 nmol/L) and sufficiency $(>50 \mathrm{nmol} / \mathrm{L})$ were noted in $33.7 \%(\mathrm{n}=1010)$ and $30.6 \%$ $(n=919)$ respectively. Hence, only $30.6 \%$ of the neonates had levels in the sufficiency range. Using a higher threshold for sufficiency, 6.7\% $(n=200)$ had 25OHD concentrations $>75$ $\mathrm{nmol} / \mathrm{L}$.

\section{Seasonal and ethnic variation in $250 H D$}

The median (IQR) 25OHD concentration was significantly lower in winter-born compared to summer-born [29.1 $(19.8,40.6) \mathrm{nmol} / \mathrm{L}$ vs $49.2(34.3,64.8) \mathrm{nmol} / \mathrm{L}$ respectively; $\mathrm{p}<0.001]$ Figure 1a. Vitamin D deficiency was also more prevalent in the winter-born babies compared to summer-born babies [52.9\% $(\mathrm{n}=794)$ vs $18.4 \%(\mathrm{n}=276)$ respectively; $\mathrm{p}<0.001]$ Figure $\mathbf{1 b}$. The median (IQR) 25OHD concentrations differed significantly among ethnic groups, as presented in box 1 below. Compared to white British, the 25OHD concentrations were significantly lower in babies of black $(p<0.001)$, Asian $(p<0.001)$, any other mixed $(p<0.001)$, mixed white and black $(\mathrm{p}<0.05)$ and any other white $(\mathrm{p}<0.05)$ background. Babies of Mixed white and Asian background also had lower median 25OHD concentrations compared to babies of white British background, but this was not statistically significant. The median 25OHD concentrations for various ethnic groups in winter and summer are shown in Figure 2. 
Box 1: Median (IQR) 25OHD for various ethnic groups.

\begin{tabular}{|lccc|}
\hline Ethnic group (n) & $\begin{array}{c}\text { Median (IQR) } \\
\text { 25OHD nmol/L }\end{array}$ & $\begin{array}{c}\text { Median (IQR) } \\
\text { 25OHD nmol/L }\end{array}$ & $\begin{array}{c}\text { Median (IQR) } \\
\text { 25OHD nmol/L }\end{array}$ \\
\hline & Total & Summer & Winter \\
\hline White British (1774) & $41.6(27.6,59.3)$ & $56.3(42.1,69.7)$ & $29.3(20.8,40.3)$ \\
\hline Mixed white and Asian (45) & $39.1(22.3,54.9)$ & $52.0(34.0,62.8)$ & $25.6(14.4,39.6)$ \\
Any other white (264) & $37.7(24.7,53.2)^{*}$ & $48.4(33.7,61.1)$ & $30.4(20.7,41.0)$ \\
Mixed white and black (94) & $33.7(21.6,50.3)^{*}$ & $45.1(33.8,59.9)$ & $25.3(16.9,36.4)$ \\
Any other mixed (156) & $32.9(20.1,47.3)^{* *}$ & $36.9(24.7,51.9)$ & $26.8(16.8,44.1)$ \\
Asian (493) & $31.3(20.1,44.0)^{* *}$ & $31.8(23.7,46.7)$ & $29.9(18.3,42.6)$ \\
Black (173) & $30.3(19.4,43.2)^{* *}$ & $38.3(26.3,49.1)$ & $24.4(15.0,34.4)$ \\
\hline
\end{tabular}

${ }^{* *} \mathrm{p}<0.001$ and ${ }^{*} \mathrm{p}<0.05$ when compared to white British 


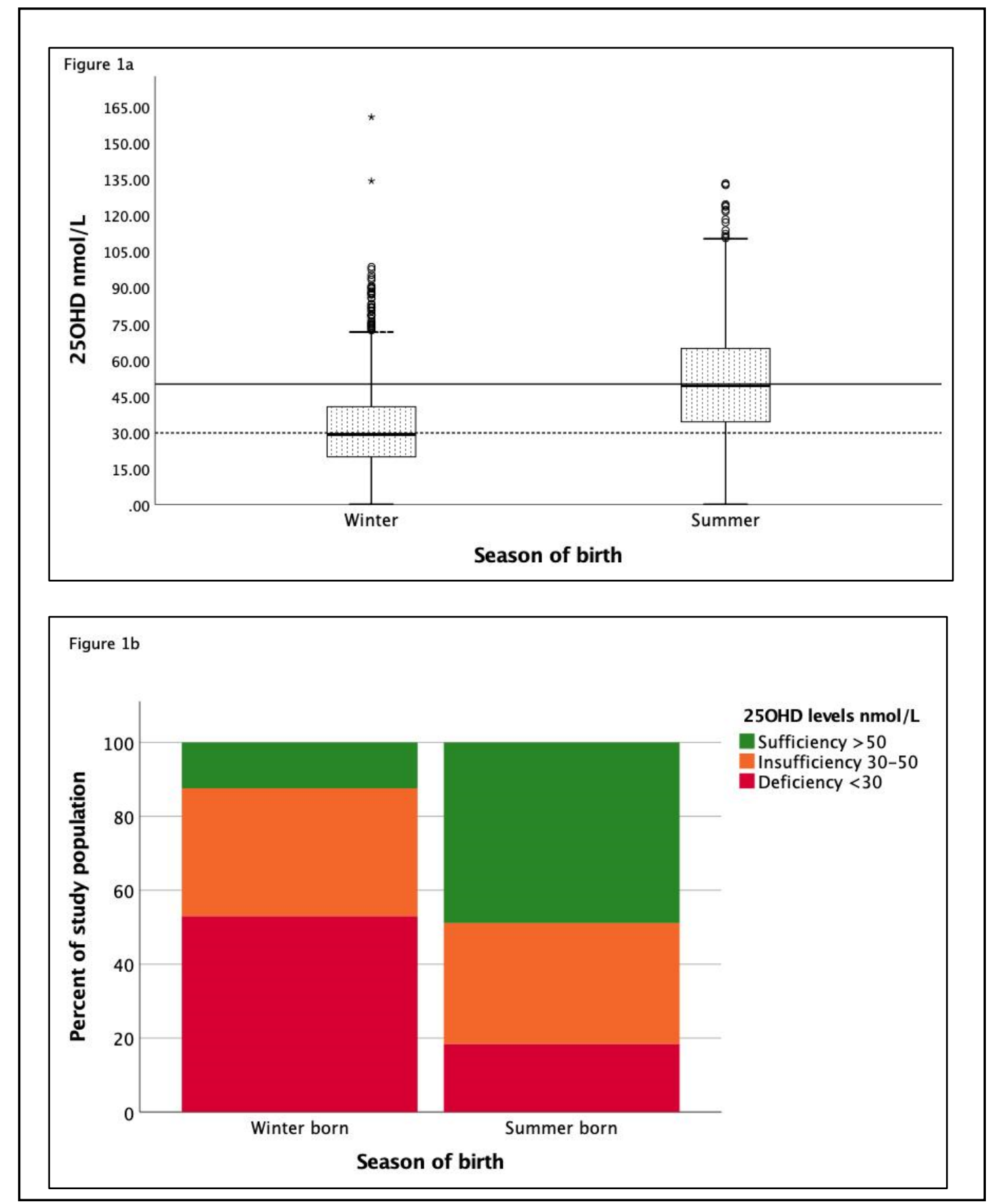

Figure 1: Figure 1a) Box plot demonstrating significantly lower median 25OHD concentrations in winter-born babies compared to summer-born babies [29.1 nmol/L vs 49.2 $\mathrm{nmol} / \mathrm{L}$ respectively; $\mathrm{p}<0.001]$. Horizontal lines are drawn at $30 \mathrm{nmol} / \mathrm{L}$ (deficiency cut-off) and $50 \mathrm{nmol} / \mathrm{L}$ (sufficiency cut-off).

Figure 1b) The proportion of deficiency, insufficiency and sufficiency in winter was $52.9 \%$, $34.6 \%$ and $12.4 \%$, respectively and in summer $18.4 \%, 32.7 \%$ and $48.9 \%$, respectively. 


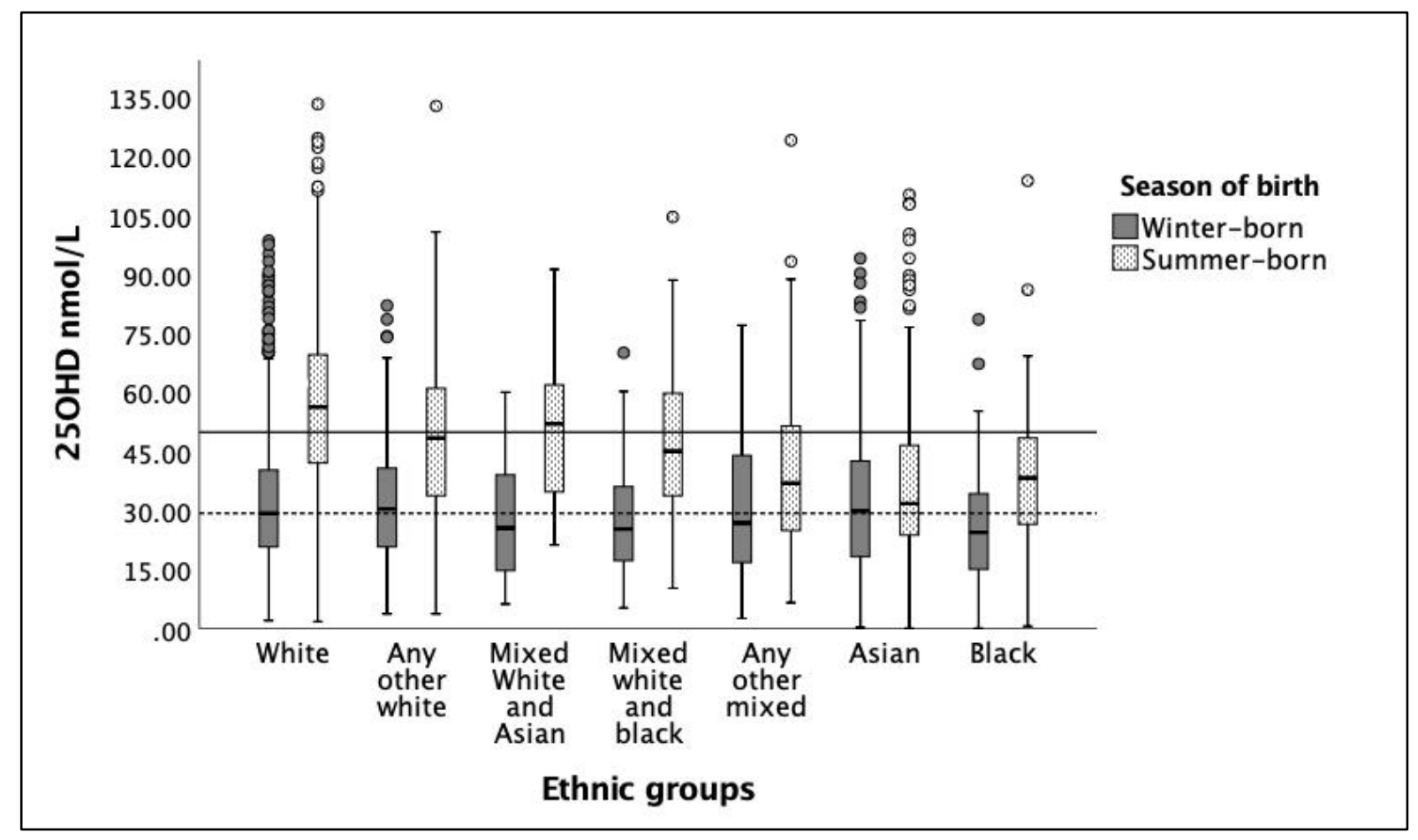

Figure 2: Median (IQR) 25OHD concentrations based on ethnicity and season of birth. When compared to white British the 25OHD concentrations were significantly lower in babies of any other white $(\mathrm{p}<0.05)$, mixed white and black $(\mathrm{p}<0.05)$, any other mixed $(p<0.001)$, Asian $(p<0.001)$ and black $(p<0.001)$ background. 
The percentage of the study group who were vitamin D deficient across both seasons was lowest in white British at $30.3 \%$ and highest in babies of Asian and black ethnic background at $47.7 \%$ and $47.4 \%$, respectively. Seasonal differences in the proportion of deficiency and insufficiency in various ethnic groups are presented in box 2 below and Figure 3a (winter) and Figure 3b (summer).

Box 2: Seasonal variation in the proportion of $250 \mathrm{HD}$ concentrations $<25 \mathrm{nmol} / \mathrm{L}$ and $\leq 50 \mathrm{nmol} / \mathrm{L}$ based on ethnicity

\begin{tabular}{|l|cc|cc|}
\hline Ethnicity & \multicolumn{2}{|c|}{ Summer } & \multicolumn{2}{c|}{ Winter } \\
\hline & \% $<\mathbf{2 5 n m o l} / \mathbf{L} \quad \mathbf{\%} \leq \mathbf{5 0 n m o l} / \mathbf{L}$ & $\mathbf{\%}<\mathbf{2 5} \mathbf{~ n m o l} / \mathbf{L}$ & $\mathbf{\%} \leq \mathbf{5 0 n m o l} / \mathbf{L}$ \\
\hline White & 3.8 & 39.2 & 36.5 & 86.7 \\
Any other white & 14.6 & 52.3 & 35.1 & 89.6 \\
\hline Black & 21.7 & 75.9 & 53.3 & 95.6 \\
Asian & 30.2 & 78.4 & 40.6 & 86.3 \\
Mixed white and Asian & 8.3 & 41.7 & 47.6 & 90.5 \\
Mixed white and Black & 17.1 & 56.1 & 49.1 & 88.7 \\
Any other mixed & 25 & 73.8 & 48.7 & 88.2 \\
\hline
\end{tabular}




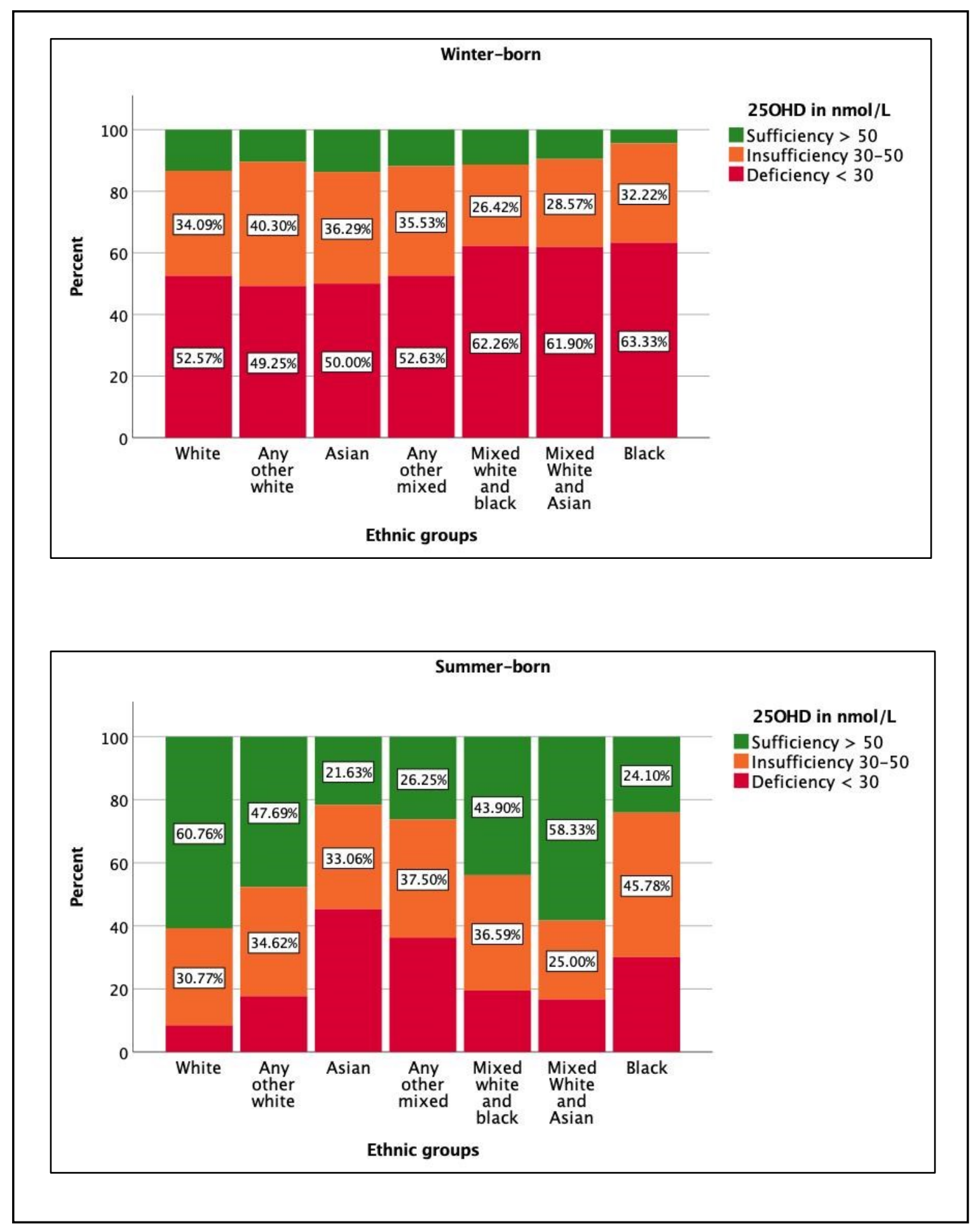

Figure 3: Bar graph representing the proportion of study population that were deficient, insufficient and sufficient according to ethnic groups in winter (3a) and summer (3b). Vertical bars are colour-coded by vitamin D status and ordered in according to decreasing sufficiency compared to white and any other white. 


\section{Determinants of 25OHD concentrations}

Parameters which were significant $(\mathrm{p}<0.05)$ on a bivariate linear regression and included in the multiple regression model were season of birth, ethnicity, gestational age, maternal age, and IMD decile. Birth weight and gender were not associated with $25 \mathrm{OHD}$ concentrations $(\mathrm{p}>0.05)$.

The results of the regression model are presented in Table 2. The statistically significant determinants of 25OHD were season of birth, ethnicity (all ethnic groups except mixed white and Asian compared to white British), gestation (prematurity and extreme prematurity compared to term gestation) and maternal age. The mean $( \pm \mathrm{SD}) 25 \mathrm{OHD}$ concentration in term, pre-term, extremely pre-term and post-term babies was $40.7( \pm 21.7), 45.9( \pm 25.2), 64.3( \pm 26.9)$ and $38.6( \pm 16.8) \mathrm{nmol} / \mathrm{L}$ respectively.

Nearly $24 \%$ (adjusted $\mathrm{R}^{2} 0.242$ ) of the variation in newborn $25 \mathrm{OHD}$ was explained by the model used, with season of birth being the major contributor at $19 \%$ (adjusted $\mathrm{R}^{2} 0.19$ ). 
Table 2: Determinants of 25OHD concentrations in a linear regression model.

\begin{tabular}{|c|c|c|c|}
\hline Determinant & $\begin{array}{l}\beta \\
\text { Standardised } \\
\text { Co-efficient }\end{array}$ & $\begin{array}{l}95 \% \text { Confidence } \\
\text { interval }\end{array}$ & $P$ value \\
\hline Season (Winter/Summer) & 0.43 & $17.70,20.46$ & 0.000 \\
\hline $\begin{array}{l}\text { Ethnicity } \\
\text { White British } \\
\text { Asian } \\
\text { Black } \\
\text { Mixed white and black } \\
\text { Any other mixed } \\
\text { Any other white } \\
\text { Mixed white and Asian }\end{array}$ & $\begin{array}{l}\text { Reference } \\
-0.17 \\
-0.13 \\
-0.05 \\
-0.09 \\
-0.05 \\
-0.02\end{array}$ & $\begin{array}{l}-12.37,-8.34 \\
-15.56,-9.35 \\
-11.17,-3.19 \\
-12.86,-6.51 \\
-6.54,-1.53 \\
-10.60,0.74\end{array}$ & $\begin{array}{l}0.000 \\
0.000 \\
0.000 \\
0.000 \\
0.002 \\
0.089\end{array}$ \\
\hline $\begin{array}{ll}\text { Gestation in weeks } & \\
\begin{array}{ll}\text { Term }>37-41 & (\mathrm{n}=2,422) \\
\text { Extreme pre-term }<28 & (\mathrm{n}=7) \\
\text { Pre-term } 28-37 & (\mathrm{n}=502) \\
\text { Post-term }>41 & (\mathrm{n}=68)\end{array}\end{array}$ & $\begin{array}{l}\text { Reference } \\
0.07 \\
0.05 \\
-0.01\end{array}$ & $\begin{array}{ll}3.13, & 8.50 \\
10.10, & 39.43 \\
-6.74, & 2.49\end{array}$ & $\begin{array}{l}0.000 \\
0.001 \\
0.367\end{array}$ \\
\hline Maternal age & 0.06 & $0.13,0.38$ & 0.000 \\
\hline $\begin{array}{l}\text { IMD deciles } \\
\begin{array}{ll}\text { Decile } 10 & \text { (least deprived) }(\mathrm{n}=136) \\
\text { Decile } 1 & (\mathrm{n}=720) \\
\text { Decile } 2 & (\mathrm{n}=501) \\
\text { Decile } 3 & (\mathrm{n}=331) \\
\text { Decile } 4 & (\mathrm{n}=260) \\
\text { Decile } 5 & (\mathrm{n}=309) \\
\text { Decile } 6 & (\mathrm{n}=217) \\
\text { Decile } 7 & (\mathrm{n}=201) \\
\text { Decile } 8 & (\mathrm{n}=175) \\
\text { Decile } 9 & (\mathrm{n}=136)\end{array}\end{array}$ & $\begin{array}{l}\text { Reference } \\
0.00 \\
0.02 \\
0.00 \\
-0.01 \\
0.00 \\
0.00 \\
0.03 \\
0.00 \\
0.00\end{array}$ & $\begin{array}{l}-3.55,3.68 \\
-2.33,5.07 \\
-3.82,3.92 \\
-4.82,3.19 \\
-3.59,4.19 \\
-3.90,4.33 \\
-1.40,6.96 \\
-3.63,4.97 \\
-4.49,4.40\end{array}$ & $\begin{array}{l}0.972 \\
0.469 \\
0.982 \\
0.690 \\
0.879 \\
0.919 \\
0.192 \\
0.760 \\
0.985 \\
\end{array}$ \\
\hline
\end{tabular}




\section{DISCUSSION}

Nearly $70 \%$ of the babies in our multi-ethnic cohort had low vitamin D status $(25 \mathrm{OHD}<50$ $\mathrm{nmol} / \mathrm{L})$. Vitamin D deficiency, insufficiency and sufficiency were noted in approximately a third each. Winter-born babies are at significant risk of deficiency, with only $15 \%$ achieving sufficient vitamin D status. The proportion of deficiency, when compared to white race $(52.5 \%$ in winter, $8.4 \%$ in summer), was much higher in the Black, Asian and Minority Ethnic (BAME) $(63.3 \%, 30.1 \%)$, mixed $(62.2 \%, 36.2 \%)$ and other white $(49.2 \%, 17.6 \%)$ ethnic groups. Season of birth, ethnicity, gestation at birth and maternal age contributed to $24 \%$ of the variation in newborn $25 \mathrm{OHD}$ concentrations.

The main strength of this study is the large, ethnically diverse newborn cohort from a high latitude country with complete data on birth weight, gestation, maternal age and ethnicity. Very few studies have assessed 25OHD on DBS obtained from NBS.[28-30] To our best knowledge, our study is the first to ascertain prevalence of neonatal vitamin D deficiency in non-archived DBS, eliminating the concern of 25OHD degradation with prolonged storage.[31] The potential limitation is the lack of data on maternal and early infant supplementation, especially since compliance with national policy on vitamin D supplementation is known to be poor.[15] In the UK, the uptakes of both infant,[13,32] and antenatal vitamin supplements,[10] remain $<20 \%$.

The high prevalence of vitamin D deficiency and insufficiency in our multi-ethnic newborn cohort, of $70 \%$, is comparable to the pooled global prevalence of $75 \%$.[33] Other studies at comparable latitude also report mean/median 25OHD concentrations below $50 \mathrm{nmol} / \mathrm{L}$.[34] We report a higher prevalence of deficiency (52.9\% in winter and $18.4 \%$ in summer) compared to the pooled European data (19.7-31.8\% in winter and $5.7-15.3 \%$ in summer),[35] which is explained by the underrepresentation of ethnic minority children and the absence of newborn data in the latter.[35] The well-recognised seasonal,[35,36] and ethnic,[37,38] variations in 
25OHD concentrations were confirmed. Most importantly, the plasma equivalent 25OHD concentrations derived from DBS reported here are comparable to other reports from DBS, $[28,39]$ and also cord serum.[29,40] These agreements across studies confirm the utility of blood spot assays in accurately determining the vitamin D status of the newborn.

The major determinant of newborn $25 \mathrm{OHD}$ concentration was the season of birth as previously reported.[39] All ethnicities, except white British and mixed white and Asian, contributed to low vitamin D status. Although vitamin D status in the UK South Asian community has been widely studied, [38,41-44] other vulnerable ethnic groups such as the black and mixed race remain less well studied, despite the high incidence of rickets in these groups.[1,45-47] The mean $25 \mathrm{OHD}$ concentration in pre-term babies was around $5 \mathrm{nmol} / \mathrm{L}$ higher than the term babies, likely owing to the use of supplements or pre-term formula feeds. No significant effect on 25OHD concentrations was observed in the post-term babies, similar to previous reports.[30,48] Low socio-economic status has been linked to vitamin D deficiency and insufficiency in children.[49-51] Socio-economic status, determined by IMD decile, was independently associated with $25 \mathrm{OHD}$ concentrations but did not contribute to the final model confirming the predominant role of sunlight and skin colour.

Our findings have profound implications for public health policies in high latitude countries. Whilst sunlight exposure is a modifiable factor, the lack of UVB at high latitude is hardly modifiable,[52] necessitating robust supplementation and/or food fortification policies. A high proportion of deficiency in our cohort suggests shortfalls in the current UK supplementation policy,[53] likely owing to lack of clarity and inconsistency among UK policy makers. Pregnant women were classed as high risk and recommended $400 \mathrm{IU}(10 \mu \mathrm{g}) / \mathrm{day}$ supplement in the letter issued by the UK Chief Medical Officers in 2012,[54] and the National Institute for Health and care excellence (NICE) guidance in 2014.[14] In addition to the general recommendation above, The Royal College of Obstetricians and Gynaecologists specifically 
recommend a higher dose of $1000 \mathrm{IU}(25 \mu \mathrm{g}) /$ day in dark skinned individuals.[15] Conversely, the most recent Public Health England guidance in 2016,[55] which was based on the Scientific Advisory Committee on Nutrition report on vitamin D and health,[7] did not make any specific supplement recommendations for pregnant women or regard them as high risk. We have previously also elaborated on the complexities of infant supplementation policy in the UK.[56] Clarity in public health policies and a unified approach is crucial for its success.

Adult vitamin $\mathrm{D}$ requirements have been extended to pregnant women due to the lack of pregnancy-specific data. Since these requirements cannot be met through diet, the IOM,[27] and global consensus for prevention of rickets,[9] recommend $600 \mathrm{IU}(15 \mu \mathrm{g}) /$ day supplements in pregnancy. A study of pregnant women in Denmark $(n=107)$ reported cord blood 25OHD concentrations $<50 \mathrm{nmol} / \mathrm{L}$ in $61 \%$ of newborns (of whom $15 \%$ had concentrations $<25$ nmol/L) despite the use of $400 \mathrm{IU} /$ day supplements in $79 \%$ of the women.[57] Antenatal supplementation should aim at preventing vitamin D deficiency in the newborn, bearing in mind that $25 \mathrm{OHD}$ concentrations in the neonate are estimated to be $50-70 \%$ of maternal concentrations.[57] A supplementation trial of pregnant white women $(n=144)$ residing in northern latitude reported that $1200 \mathrm{IU}(30 \mu \mathrm{g}) /$ day supplement achieved sufficiency (25OHD $\geq 50 \mathrm{nmol} / \mathrm{L}$ ) in almost all women and prevented deficiency (cord $25 \mathrm{OHD}<30 \mathrm{nmol} / \mathrm{L}$ ) in $95 \%$ of neonates.[34] Similar dose-finding studies in ethnic minority population are warranted.

Supplement use in the UK population is low,[58] as seen in the case of folic acid supplementation in pregnancy.[59] Only 27\% of women aged 19-64 years reported taking vitamin D supplements in the National Diet and Nutrition Survey.[58] In a longitudinal study of pregnant women in Southampton, UK, only $15 \%(n=30 / 198)$ reported using vitamin D supplements.[10] Uptake of infant supplementation is equally poor,[13,32] and unsurprisingly the unsupplemented newborn with low reserve, in particular from BAME brackground, likely goes on to develop hypocalcaemic complications and rickets.[1,45,46,60-63] Countries with 
poor adherence to supplements,[13,62] and/or a high proportion of immigrant population, $[56,64,65]$ have therefore seen a resurgence in nutritional rickets.[66,67] A 90-166 fold higher incidence of rickets seen in the UK children of BAME background, compared to their white counterparts, $[46,68]$ is consistent with our observation of lower $25 \mathrm{OHD}$ concentrations seen at birth reported here and the lack of rigid infant supplementation system.[56] Universal supplementation (irrespective of feeding mode) and greater adherence $(>90 \%)$ to infant supplementation can mitigate these risks as demonstrated by a Danish study $(\mathrm{n}=108)$ where the proportion of newborns with $25 \mathrm{OHD}$ concentrations $<50 \mathrm{nmol} / \mathrm{L}$ decreased from $61 \%$ at birth to $4 \%$ at 4 months; with none having concentrations below $25 \mathrm{nmol} / \mathrm{L}$. [57] Universal supplementation of pregnant women (irrespective of risk factors) also enhances adherence.[69] Clear operational policies,[14] and national monitoring of supplement uptake,[13] are warranted in the UK. Additionally, measuring 25OHD on DBS samples from NBS at regular intervals could be considered to monitor the effect of these interventions.

Vitamin D deficiency in the UK BAME residents and immigrants is a long-standing problem and considered a symbol of health inequality.[56] We have previously elaborated on the UK's progression from eradication of rickets through rationing, food fortification and supplementation of infants and pregnant women with cod-liver oil during world war 2 to its subsequent resurgence ever since the 1960s.[56] The higher prevalence of deficiency in the UK population is in stark contrast to reports from Nordic countries where supplement use is generally high,[70,71] and/or widespread fortification is adopted.[70] Finland serves as a prime example demonstrating a steady improvement in population $25 \mathrm{OHD}$ status [ from $48 \mathrm{nmol} / \mathrm{L}$ in $2000(\mathrm{n}=6134)$ to $65 \mathrm{nmol} / \mathrm{L}$ in $2011(\mathrm{n}=4051)]$ following systematic fortification of fluid milk products $(0.5 \mu \mathrm{g} / 100 \mathrm{~g}$ in 2003 , doubled to $1 \mu \mathrm{g} / 100 \mathrm{~g}$ in 2010) and increased supplement use (11\% to 41\%).[72] Even among non-supplement users, 91\% achieved sufficiency.[72] The 2011 Finnish health survey reported high-normal 25OHD concentrations [ $>125 \mathrm{nmol} / \mathrm{L}(>50$ 
$\mu \mathrm{g} / \mathrm{L})$ ] in only $0.2 \%(\mathrm{n}=8 / 4051)$, where the majority $(\mathrm{n}=7 / 8)$ were supplement users.[72] The prevalence of maternal and newborn vitamin D deficiency in Finland has reduced from 60$70 \%$ in $2007(n=125)$ to $1 \%$ in $2016(n=584)$ due to enhanced supplement use (increase from 40 to $80 \%$ ) and consumption of fortified food.[73] Hence, a combined approach with fortification and supplementation of high risk groups is the cost-effective way forward for the UK,[74] to improve population health and eliminate social inequalities.[75] Urgent review of the UK public health policies relating to vitamin D supplementation and their implementation, $[56,65]$ is warranted to address the preventable health consequences of vitamin D deficiency in infancy.

\section{CONCLUSIONS}

Vitamin D deficiency is highly prevalent in all babies born in the UK, especially in winter months. The high proportion of dark-skinned infants with low vitamin D status, demonstrates the failure of the UK's national antenatal supplementation programme in protecting these ethnic groups, who are well recognised to be at a high risk of vitamin D deficiency. Evidently, the combination of poor antenatal and infant supplementation has resulted in the resurgence of the "English disease" in the UK, where hypocalcaemic seizures and rickets in dark-skinned infants are not a rarity. We conclude that vitamin D supplementation programmes should be delivered and monitored like immunisation programmes, and food fortification implemented. The successful example of the effect of vitamin D food fortification in other high latitude countries, such as Finland, should guide the design of a national fortification programme. We demonstrate that analysis of DBS $25 \mathrm{OHD}$ can serve as a key performance indicator for the success of antenatal supplementation programmes and thereby inform preventative public health interventions. 


\section{Acknowledgements:}

We are indebted to Peter Nightingale (University Hospital Birmingham, Birmingham, UK) for statistical guidance and advice.

\section{Contritbutory roles:}

SU: Funding acquisition, methodology, supervision, data curation, formal analysis, visualization and original draft writing. SN and JL: Investigation and data curation. RD, PG and MAP: Data curation, methodology, resources, supervision and review and editing of manuscript. RDunn, WF and JT: Investigation, sample analysis, data curation, resources and review and editing of manuscript. WH: Conceptualization, funding acquisition, methodology, supervision, visualization and intellectual editing of manuscript.

\section{Transparency declaration:}

The lead author (SU) and guarantor affirms that the manuscript is an honest, accurate, and transparent account of the study being reported. No important aspects of the study have been omitted.

\section{Funding:}

The research fellow (SU) was funded by a Global challenges research scholarship by the University of Birmingham, Birmingham, UK. Additional funding for consumables was received from Internis pharmaceuticals limited, c/o Thornton and Ross 1td. The funders have not had any input into the design, conduct and reporting of the study.

\section{Competing interests:}

SU, WH and WF have previously received speaker's fee from Internis pharmaceuticals limited, c/o Thornton and Ross 1td. The other authors (SN, JL, RD, PG, MAP, RDunn, JT) do not have any relevant conflict of interest to declare.

\section{Patient and public involvement:}

Patients or the public were not involved in the design, or conduct, or reporting, or dissemination plans of our research. 


\section{References:}

1 Uday S, Fratzl-Zelman N, Roschger P, et al. Cardiac, bone and growth plate manifestations in hypocalcemic infants: revealing the hidden body of the vitamin D deficiency iceberg. BMC Pediatr 2018;18:183. doi:10.1186/s12887-018-1159-y

2 Uday S, Högler W. Spot the silent sufferers: A call for clinical diagnostic criteria for solar and nutritional osteomalacia. J Steroid Biochem Mol Biol 2019;188:141-6. doi:10.1016/j.jsbmb.2019.01.004

3 Ladhani S, Srinivasan L, Buchanan C, et al. Presentation of vitamin D deficiency. Arch Dis Child 2004;89:781-4. doi:10.1136/adc.2003.031385

$4 \quad$ Elidrissy ATH. The Return of Congenital Rickets, Are We Missing Occult Cases? Calcif Tissue Int 2016;99:227-36. doi:10.1007/s00223-016-0146-2

5 Erdeve Ö, Atasay B, Arsan S, et al. Hypocalcemic seizure due to congenital rickets in the first day of life. Turk J Pediatr 2007;49:301-3.

6 Innes AM, Seshia MM, Prasad C, et al. Congenital rickets caused by maternal vitamin D deficiency. Paediatr Child Health (Oxford) 2002;7:455-8. doi:10.1093/pch/7.7.455

7 Scientific Advisory Committee on Nutrition. Vitamin D and Health 2016. 2016. doi:10.1007/s00198-015-3440-3

8 Cockburn F, Belton NR, Giles MM, et al. Maternal vitamin D intake and mineral metabolism in mothers and their newborn infants. Br Med $J$ 1980;281:11-4. doi:10.1136/bmj.281.6232.11

9 Munns CF, Shaw N, Kiely M, et al. Global consensus recommendations on prevention and management of nutritional rickets. Horm Res Paediatr 2016;85:83-106. doi:10.1159/000443136

10 Javaid MK, Crozier SR, Harvey NC, et al. Maternal vitamin D status during pregnancy and childhood bone mass at age 9 years: A longitudinal study. Lancet 2006;367:36-43. doi:10.1016/S0140-6736(06)67922-1

11 Wei SQ, Qi HP, Luo ZC, et al. Maternal vitamin D status and adverse pregnancy outcomes: A systematic review and meta-analysis. J Matern Neonatal Med 2013;26:889-99. doi:10.3109/14767058.2013.765849

12 Aghajafari F, Nagulesapillai T, Ronksley PE, et al. Association between maternal serum 25-hydroxyvitamin D level and pregnancy and neonatal outcomes: Systematic review and meta-analysis of observational Studies. Br Med J 2013;346:1-14. doi:10.1136/bmj.f1169

13 Uday S, Kongjonaj A, Aguiar M, et al. Variations in infant and childhood Vitamin D supplementation programs across Europe and factors influencing adherence. Endocr Connect 2017;6:667-75. doi:10.1530/EC-17-0193

14 National Institute for Health and care excellence. Vitamin D: supplement use in specific population groups. 2014.https://www.nice.org.uk/guidance/ph56

15 Royal College of Obstetricians and Gynaecologists. Vitamin D in Pregnancy. Scientific Impact Paper No. 43. 2014. https://www.rcog.org.uk/globalassets/documents/guidelines/scientific-impactpapers/vitamin_d_sip43_june14.pdf

16 NDNS. National Diet and Nutrition Survey Results from Years 5 and 6 (combined) of the Rolling Programme (2012/2013 - 2013/2014). 2016. https://www.gov.uk/government/uploads/system/uploads/attachment_data/file/551352/ NDNS_Y5_6_UK_Main_Text.pdf

17 Eyles D, Anderson C, Ko P, et al. A sensitive LC/MS/MS assay of $25 \mathrm{OH}$ vitamin D3 and 25OH vitamin D2 in dried blood spots. Clin Chim Acta 2009;403:145-51. 
doi:10.1016/j.cca.2009.02.005

18 Ball N, Tang J, Fraser WD, et al. Development of a quantitative LC-MS/MS analysis for measurement of circulating 25-hydroxyvitamin D using Volumetric Absorptive Microsampling (VAMS). Mass Matters 2017;:18-21.

19 Hoeller U, Baur M, Roos FF, et al. Application of dried blood spots to determine Vitamin D status in a large nutritional study with unsupervised sampling: The Food4Me project. Br J Nutr 2016;115:202-11. doi:10.1017/S0007114515004298

20 Ministry of Housing Communities and Local Government. English Indices of deprivation 2019. 2019.http://imd-by-postcode.opendatacommunities.org/imd/2019

21 Department for Communities and Local Government. The English Index of Multiple Deprivation (IMD) 2015 - Guidance. 2015.

doi:https://www.gov.uk/government/statistics/english-indices-of-deprivation-2015

22 Office of National Statistics. Ethnic group, National Identity and Religion. 2016.https://webarchive.nationalarchives.gov.uk/20160106185816/http://www.ons.go v.uk/ons/guide-method/measuring-equality/equality/ethnic-nat-identity-religion/ethnicgroup/index.html\#2

23 Tang J, Nicholls H, Ball N, et al. Assessment of vitamin D status using MitraTM volumetric absorptive microsampling (VAMS) device. In: Annual Meeting of the American Society for Bone and Mineral Research, Colorado Convention Center, Denver, CO, USA. 2017. doi:10.1002/jbmr.3363

24 Jopling J, Henry E, Wiedmeier SE, et al. Reference ranges for hematocrit and blood hemoglobin concentration during the neonatal period: Data from a multihospital health care system. Pediatrics 2009;123:e333-7. doi:10.1542/peds.2008-2654

25 Kayiran SM, Özbek N, Turan M, et al. Significant differences between capillary and venous complete blood counts in the neonatal period. Clin Lab Haematol 2003;25:916. doi:10.1046/j.1365-2257.2003.00484.x

26 Public Health England. NHS Newborn Blood Spot Screening Programme Code of practice for the retention and storage of residual newborn blood spots. 2018. https:/www.gov.uk/government/uploads/system/uploads/attachment_data/file/670641/ Code_of_Practice_for_the_Retention_and_Storage_of_Residual_Newborn_Blood_Sp ots.pdf

27 Ross AC, Manson JAE, Abrams SA, et al. The 2011 report on dietary reference intakes for calcium and vitamin D from the Institute of Medicine: What clinicians need to know. J Clin Endocrinol Metab 2011;9:53-8. doi:10.1210/jc.2010-2704

28 Keller A, Frederiksen P, Händel MN, et al. Environmental and individual predictors of 25-hydroxyvitamin D concentrations in Denmark measured from neonatal dried blood spots: The D-tect study. Br J Nutr 2019;121:567-75.

doi:10.1017/S0007114518003604

29 Eyles DW, Morley R, Anderson C, et al. The utility of neonatal dried blood spots for the assessment of neonatal vitamin D status. Paediatr Perinat Epidemiol 2010;24:3038. doi:10.1111/j.1365-3016.2010.01105.x

30 Keller A, Händel MN, Frederiksen P, et al. Concentration of 25-hydroxyvitamin D from neonatal dried blood spots and the relation to gestational age, birth weight and Ponderal Index: The D-Tect study. Br J Nutr 2018;119:1416-23.

doi:10.1017/S0007114518000879

31 Heath AK, Williamson EJ, Ebeling PR, et al. Measurements of 25-hydroxyvitamin D concentrations in archived dried blood spots are reliable and accurately reflect those in Plasma. J Clin Endocrinol Metab 2014;99:3319-24. doi:10.1210/jc.2014-1269

32 Jessiman T, Cameron A, Wiggins M, et al. A qualitative study of uptake of free vitamins in England. Arch Dis Child 2013;98:587-91. doi:10.1136/archdischild-2013- 


\section{8}

33 Saraf R, Morton SMB, Camargo CA, et al. Global summary of maternal and newborn vitamin D status - a systematic review. Matern Child Nutr 2016;12:647-68.

doi: $10.1111 / \mathrm{mcn} .12210$

34 O'Callaghan KM, Hennessy Á, Hull GLJ, et al. Estimation of the maternal Vitamin D intake that maintains circulating 25-hydroxyVitamin $\mathrm{D}$ in late gestation at a concentration sufficient to keep umbilical cord sera $\geq 25-30 \mathrm{nmol} / \mathrm{L}$ : a dose-response, double-blind, randomized placebo-controlled trial in pre. Am J Clin Nutr 2018;108:7791. doi:10.1093/ajen/nqy064

35 Cashman, K D. Dowling KG. Vitamin D deficiency in Europe: pandemic? Am J Clin Nutr 2016;103:1033-44. doi:10.3945/ajen.115.120873.Am

36 Hyppönen E, Power C. Hypovitaminosis D in British adults at age 45y: nationwide cohort study on dietary and lifestyle predictors. Am J Clin Nutr 2007;85:860-8. doi:85/3/860 [pii]

37 Yu CKH, Sykes L, Sethi M, et al. Vitamin D deficiency and supplementation during pregnancy. Clin Endocrinol (Oxf) 2009;70:685-90. doi:10.1111/j.13652265.2008.03403.x

38 Whitelaw DC, Scally AJ, Tuffnell DJ, et al. Associations of circulating calcium and 25-hydroxyvitamin D with glucose metabolism in pregnancy: A cross-sectional study in European and south Asian women. J Clin Endocrinol Metab 2014;99:938-46. doi:10.1210/jc.2013-2896

39 Smith CA, Sun C, Pezic A, et al. Determinants of Neonatal Vitamin D Levels as Measured on Neonatal Dried Blood Spot Samples. Neonatology 2017;111:153-61. doi:10.1159/000448680

40 Cadario F, Savastio S, Magnani C, et al. High prevalence of vitamin D deficiency in native versus migrant mothers and newborns in the North of Italy: A call to act with a stronger prevention program. PLoS One 2015;10. doi:10.1371/journal.pone.0129586

41 Darling AL, Hart KH, MacDonald HM, et al. Vitamin D deficiency in UK South Asian Women of childbearing age: A comparative longitudinal investigation with UK Caucasian women. Osteoporos Int 2013;24:477-88. doi:10.1007/s00198-012-1973-2

42 Kift R, Berry JL, Vail A, et al. Lifestyle factors including less cutaneous sun exposure contribute to starkly lower vitamin D levels in U.K. South Asians compared with the white population. Br J Dermatol 2013;169:1272-8. doi:10.1111/bjd.12518

43 Sulaiman RA, Sharratt CL, Lee PW, et al. Ethnic differences in umbilical cord blood vitamin D and parathyroid hormone South Asians compared to Whites born in the UK. J Matern Neonatal Med 2010;23:1315-7. doi:10.3109/14767051003653286

44 Farrar MD, Kift R, Felton SJ, et al. Recommended summer sunlight exposure amounts fail to produce sufficient vitamin D status in UK adults of South Asian origin. Am J Clin Nutr 2011;94:1219-24. doi:10.3945/ajen.111.019976

45 Basatemur E, Sutcliffe A. Incidence of hypocalcemic seizures due to vitamin D deficiency in children in the United Kingdom and Ireland. J Clin Endocrinol Metab 2015;100:E91-5. doi:10.1210/jc.2014-2773

46 Julies P, Lynn RM, Pall K, et al. Nutritional rickets under 16 years : UK surveillance results. Arch Dis Child Published Online First: 2020. doi:10.1136/archdischild-2019317934

47 Hannam S, Lee S, Sellars M. Severe vitamin D deficient rickets in black AfroCaribbean children. Arch Dis Child 2004;89:91-2.

48 Hossain N, Khanani R, Hussain-Kanani F, et al. High prevalence of vitamin D deficiency in Pakistani mothers and their newborns. Int J Gynecol Obstet 2011;112:229-33. doi:10.1016/j.ijgo.2010.09.017 
49 Basatemur E, Horsfall L, Marston L, et al. Trends in the Diagnosis of Vitamin D Deficiency. Pediatrics 2017;139:e20162748. doi:10.1542/peds.2016-2748

50 Absoud M, Cummins C, Lim MJ, et al. Prevalence and predictors of vitamin D insufficiency in children: A great britain population based study. PLoS One 2011;6:611. doi:10.1371/journal.pone.0022179

51 Tolppanen AM, Fraser A, Fraser WD, et al. Risk factors for variation in 25hydroxyvitamin D 3and D 2 concentrations and vitamin D deficiency in children. $J$ Clin Endocrinol Metab 2012;97:1202-10. doi:10.1210/jc.2011-2516

52 Majeed H, Moore GWK. Impact of Multidecadal Climate Variability on United Kingdom Rickets Rates. Sci Rep 2017;7:1-6. doi:10.1038/s41598-017-16058-1

53 Hyppönen E, Boucher BJ. Avoidance of vitamin D deficiency in pregnancy in the United Kingdom: The case for a unified approach in National policy. Br J Nutr 2010;104:309-14. doi:10.1017/S0007114510002436

54 Letter from UK Chief Medical Officers. Vitamin D - Advice on Supplements for At Risk Groups. 2012.https://www.gov.uk/government/publications/vitamin-d-advice-onsupplements-for-at-risk-groups

55 Public Health England. PHE publishes new advice on vitamin D. 2016.https://www.gov.uk/government/news/phe-publishes-new-advice-on-vitamin-d

56 Uday S, Högler W. Prevention of rickets and osteomalacia in the UK: political action overdue. Arch Dis Child 2018;103:901-6. doi:10.1136/archdischild-2018-314826

57 við Streym S, Kristine Moller U, Rejnmark L, et al. Maternal and infant vitamin D status during the first 9 months of infant life-a cohort study. Eur J Clin Nutr 2013;67:1022-8. doi:10.1038/ejen.2013.152

58 Bates B, Lennox A, Prentice A, et al. National Diet and Nutrition Survey: Results from Years 1, 2, 3 and 4 (combined) of the Rolling Programme. 2014;4:1-27. doi:2014051

59 Inskip HM, Crozier SR, Godfrey KM, et al. Women's compliance with nutrition and lifestyle recommendations before pregnancy: General population cohort study. BMJ 2009;338:b481. doi:10.1136/bmj.b481

60 Ahmed SF, Franey C, McDevitt H, et al. Recent trends and clinical features of childhood vitamin D deficiency presenting to a children's hospital in Glasgow. Arch Dis Child 2011;96:694-6. doi:10.1136/adc.2009.173195

61 Robinson PD, Högler W, Craig ME, et al. The re-emerging burden of rickets: a decade of experience from Sydney. Arch Dis Child 2006;91:564-8. doi:10.1136/adc.2004.069575

62 Munns CF, Simm PJ, Rodda CP, et al. Incidence of vitamin D deficiency rickets among Australian children: An Australian Paediatric Surveillance Unit study. Med J Aust 2012;196:466-8. doi:10.5694/mja11.10662

63 Wheeler BJ, Dickson NP, Houghton LA, et al. Incidence and characteristics of Vitamin D deficiency rickets in New Zealand children: A New Zealand Paediatric Surveillance Unit study. Aust N Z J Public Health 2015;39:380-3. doi:10.1111/17536405.12390

64 Thacher TD, Pludowski P, Shaw NJ, et al. Nutritional rickets in immigrant and refugee children. Public Health Rev 2016;37:1-10. doi:10.1186/s40985-016-0018-3

65 Högler W, Munns CF. Rickets and osteomalacia: a call for action to protect immigrants and ethnic risk groups. Lancet Glob Heal 2016;4:e229-30. doi:10.1016/S2214-109X(16)00061-9

66 Goldacre M, Hall N, Yeates DGR. Hospitalisation for children with rickets in England: A historical perspective. Lancet 2014;383:597-8. doi:10.1016/S0140-6736(14)602117 
67 Uday S, Högler W. Nutritional Rickets and Osteomalacia in the Twenty-first Century: Revised Concepts, Public Health, and Prevention Strategies. Curr Osteoporos Rep 2017;15:293-302. doi:10.1007/s11914-017-0383-y

68 Uday S, Högler W. Response letter to Nutritional rickets under 16 years: UK surveillance results. Arch. Dis. Child.

2020.https://adc.bmj.com/content/105/6/587.responses\#response-letter-to-nutritionalrickets-under-16-years-uk-surveillance-results

69 Moonan M, Hanratty B, Whitehead M. PS16 Which is more Effective, A Universal or Targeted Approach, to Implementing the National Healthy Start Programme? A Mixed Methods Study. J Epidemiol Community Health 2012;66:A44-45. doi:10.1136/jech2012-201753.115

70 Itkonen ST, Andersen R, Björk AK, et al. Vitamin D status and current policies to achieve adequate vitamin D intake in the Nordic countries. Scand J Public Health 2020;:1-12. doi:10.1177/1403494819896878

71 Ramnemark A, Norberg M, Pettersson-Kymmer U, et al. Adequate vitamin D levels in a Swedish population living above latitude $63^{\circ} \mathrm{N}$ : The 2009 Northern Sweden MONICA study. Int J Circumpolar Health 2015;74:27963. doi:10.3402/ijch.v74.27963

72 Jääskeläinen T, Itkonen ST, Lundqvist A, et al. The positive impact of general Vitamin $\mathrm{D}$ food fortification policy on Vitamin D status in a representative adult Finnish population: Evidence from an 11-y follow-up based on standardized 25hydroxyVitamin D data. Am J Clin Nutr 2017;105:1512-20. doi:10.3945/ajen.116.151415

73 Hauta-alus HH, Holmlund-Suila EM, Rita HJ, et al. Season, dietary factors, and physical activity modify 25 -hydroxyvitamin D concentration during pregnancy. Eur $J$ Nutr 2018;57:1369-79. doi:10.1007/s00394-017-1417-z

74 Aguiar M, Andronis L, Pallan M, et al. The economic case for prevention of population vitamin D deficiency: a modelling study using data from England and Wales. Eur J Clin Nutr 2019;74:825-833. doi:10.1038/s41430-019-0486-X

75 Aguiar M, Högler W. Prevention of vitamin D deficiency improves population health, social inequalities and health care budgets. Eur J Public Health 2020;30:392-3. 
